\title{
Propriety of osteosynthesis in lateral fractures of the proximal femur
}

\author{
Silvio Demitri \\ Policlinico "Salus", Trieste, Italy
}

\begin{abstract}
SUMMARY
Understanding dislocation variability in complex proximal femur fractures and the relationships with the pattern of fractures may play a crucial role in choosing the right type of implant. Comminution of the intertrochanteric area, incompetency of the lateral wall and trochanteric support are difficult to evaluate on plain X-rays and sometimes even in CT. Most of the complications belong to typical fracture patterns: A3 and so-called "reverse" A2 in AO classification. Cefalo Medullary Nails (CFN) may not be superior to Sliding Hip Screw plates (SHS) in peculiar type of fractures lacking lateral buttresses able to restrain the lateralization of the proximal head-neck fragment. Lateral trochanteric support and antirotational device in the head-neck complex may reduce secondary dislocation, non union or hardware failure complications. In this paper, a correlation between osteo-synthesis and stability of the metal-bone construct is discussed.
\end{abstract}

Key words: proximal femur fracture, lateral femoral fractures, proximal femur osteosynthesis

Received: January 20, 2020

Accepted: February 15, 2020

\section{Correspondence}

Silvio Demitri

Policlinico "Salus", via Bonaparte 4,

43123 Trieste, Italy

E-mail: demitri.silvio@gmail.com

Conflict of interest

The Author declares no conflict of interest

How to cite this article: Demitri S. Propriety of osteosynthesis in lateral fractures of the proximal femur. Lo Scalpello 2020;34:74-6. https://doi. org/10.36149/0390-5276-012

(C) Ortopedici Traumatologi Ospedalieri d'Italia (O.T.O.D.i.) 2020

\section{(c) (1) $(9)$}

This is an open access article distributed in accordance with the CC-BY-NC-ND (Creative Commons Attribution-NonCommercial-NoDerivatives 4.0 International) license. The article can be used by giving appropriate credit and mentioning the license, but only for non-commercial purposes and only in the original version. For further information: https://creativecommons.org/licenses/by-nc-nd/4.0/deed.en

\section{Lateral complex fractures}

The most important criteria, beyond $\mathrm{A} 2$ and $\mathrm{A} 3 \mathrm{AO}$ classification, to qualify complex fractures are the comminution and/or dislocation of fragments that are able to compromise the stability of the hardware-bone construct.

Major complication rates are related to: peri- and intratrochanteric comminuted fractures, dislocation of the medial wall (including the lesser trochanter), weak lateral buttress, inter-fragmentary instability after reduction or irriducibility ${ }^{1-3}$. These radiographic key points are often difficult to assess on standard Rx obtained in emergency ${ }^{1}$.

AO A3, so called "inverse intertrochanteric" fractures present lateral wall incompetency. The great trochanter is often displaced and fracturated and the head-neck complex presents a poor contact with lateral proximal structures (great trochanter and lateral wall). Diaphyseal extension from the proximal fracture site adds even more instability and reduction problems to this type fractures (Fig. 1).

\section{Problems with fixation and secondary displacement}

Weight-bearing and antigravity movements can jeopardize the stability of the bonemetal construct ${ }^{1,4,5}$. There are primarily 3 types of solicitations over the construct concurring to a secondary dislocation:

1. Rotation of the head-neck complex: if the intertrochanteric area is comminuted and there is a poor contact between head-neck fragment and lateral 


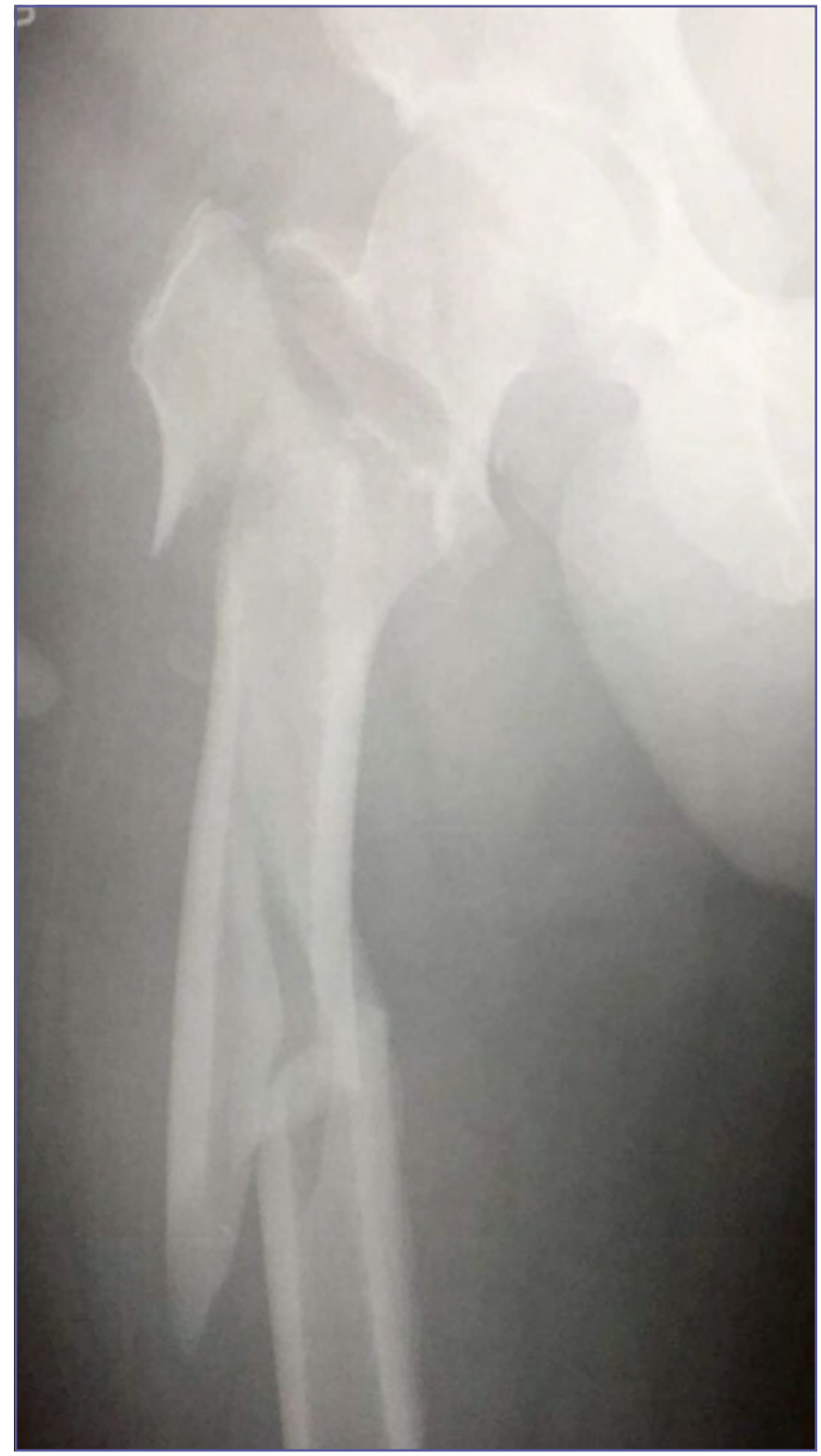

Figure 1. "Inverse" intertrochanteric fracture with diaphyseal extension.

structures, the rotation of the head-neck complex will increase the varus deformity and telescopage with impaction. The combination of rotational and axial solicitations will increase the risk of cut-in and cut-out of the dynamic cervical screw or blade.

2. Lateral compaction: usually occurs when the intertrochanteric area is comminuted. A relative shortening of the femoral neck compacting the rhyme may be useful to stabilize the fracture site and to prevent stress failure over the implant, however an eccessive shortening (over $20 \mathrm{~mm}$ or $1 / 3$ of the femoral neck) will change the lever of the medium gluteus, resulting in a

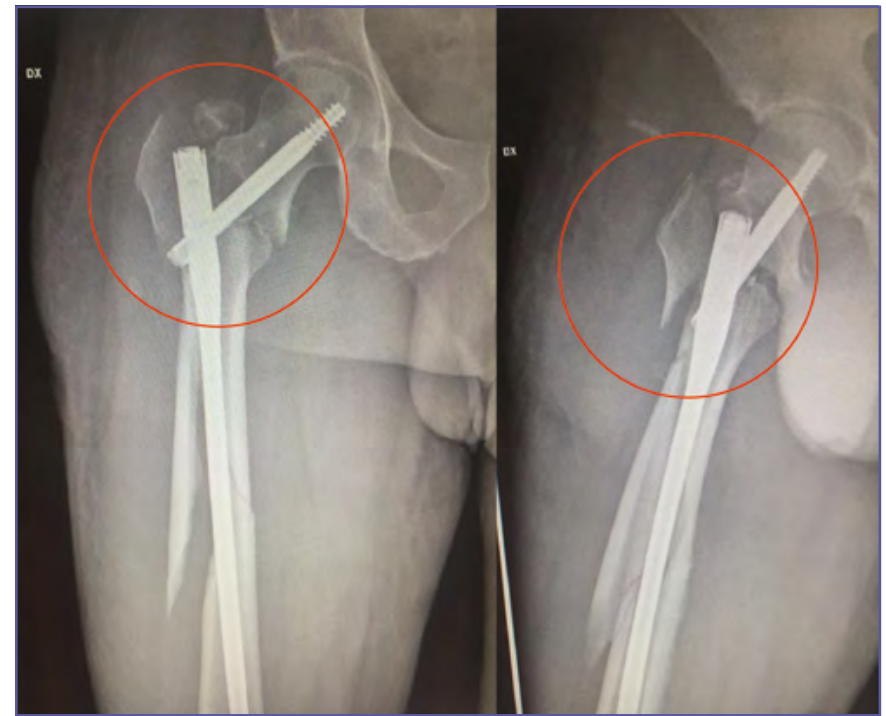

Figure 2. There is no fixation of the lateral structures. High stress forces are concentrated on the nail to prevent secondary dislocation.

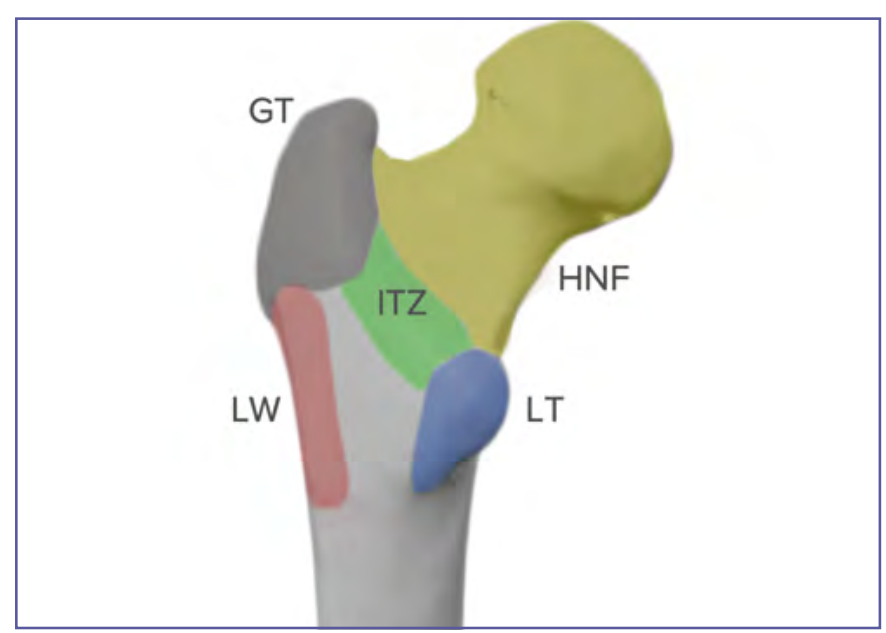

Figure 3. Areas in proximal femur related to implants (from Regazzoni et al., 2018, mod.) '.

Trendelemburg effect, and limping. Excessive lateral impaction in early follow-up X-rays, arouses suspicions when the lateral trochanteric structures are disruped: it can lead to a progressive lateral translation, cut in and hardware failure.

3. Lateral shifting: it may occur when the entire lateral buttress of the proximal femur is interrupted and the intertrochanteric area is comminuted ${ }^{1,2,4,6}$. Great trochanter and lateral wall result ineffective. The final effect is an excessive lateral compaction with telescopage and sliding. High bending and torsional forces concentrate over the implant increasing the risk of hardware failure. 


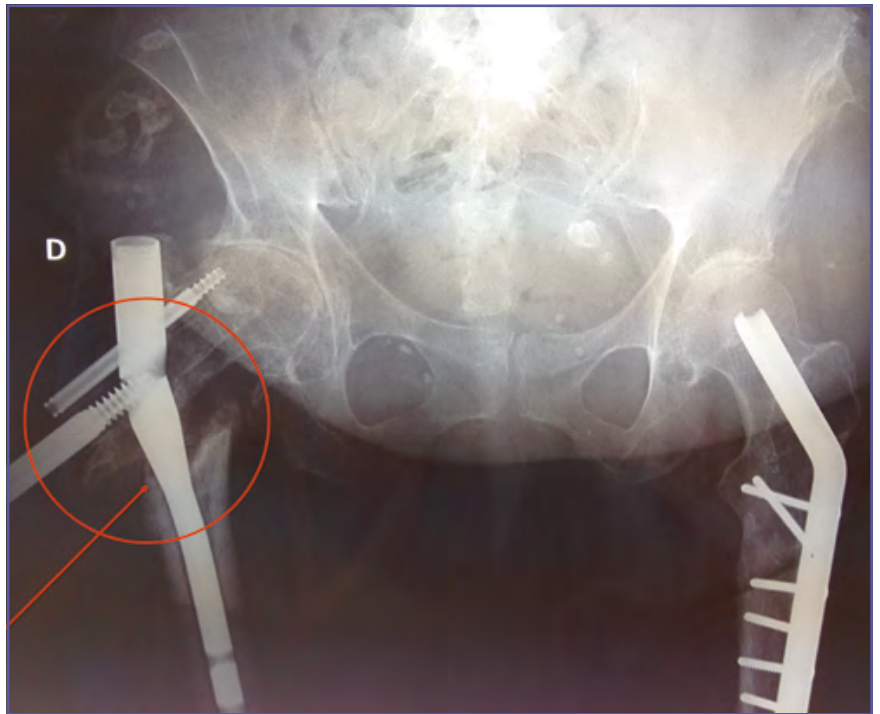

Figure 4. Lateral sliding " $z$ " effect and hardware failure in lateral structure breakage.

\section{Considerations on implants}

Sliding hip screw plates (SHS) and cephalo-medullary nails (CMN) are widespread fixation systems for the treatment of proximal femoral fractures. Few (mainly nails) present a double screw fixation system in the neck-head area. Distal static or dynamic blockage is available in almost all CFN, while dynamic features of extramedullary systems rely only on proximal sliding screw(s).

In the last 20 years, most orthopedic surgeons grew up discussing about superiority of $\mathrm{CMN}$ in the treatment of "unstable" lateral proxinal femoral fractures 2,4,6. While SHS plates usually do not provide any restrain in the upper trochanteric area, indeed the proximal intertrochantericmetaphyseal segment of a CMN acts as a buttress against the lateralization of the neck-head complex ${ }^{1,2,4,6}$. However, the disruption of the trochanter, intertrochanteric area and lateral wall, may lead to an unpreventable lateral dislocation "around" the nail.

For some SHS plates a proximal extension stabilizing as an external buttress the trochanter. Some pioneering systems with an extra-medullary plate connected to a CMN have been recently proposed ${ }^{7}$.

\section{Discussion and conclusions}

"Lateral complex" fractures of the proximal femur are at a high risk of complications. To prevent secondary dislocation some precautions have to be considered:

- to neutralize rotational dislocation of the head-neck fragment, a double-barrel screw system in the may performs better than a single screw system. The role of anti-rotational device - as far as useful to increase the rotational stability - is still to be specified (eg. spiral blade - Synthes TM or u-blade - Stryker TM).

- CMNs act as a buttress in the intertrochanteric and metaphyseal area, and as such are useful to prevent excessive telescoping and shortening ${ }^{1-3}$, but, in case of intertrochanteric comminution and lateral buttress disruption, they may be ineffective.

- once trochanter dislocation and lateral wall are disrupted, an extramedullary plate support may be useful to reduce the lateral shifting of the head-neck complex. If the diaphyseal extension of the fracture involves the lateral wall at the transition between trochanter and diaphysis, reduction and fixation of the diaphyseal fragment reduces the possibility of lateral shifting.

\section{References}

1 Regazzoni P, Fernández Dell'Oca A, Berlusconi $\mathrm{M}$, et al. Description and understanding of proximal femur fractures using coloured 3D models. ICUC, 2018.

2 Bredbenner TL, Snyder SA, Mazloomi FR, et al. Subtrochanteric fixation stability depends on discrete fracture surface points. Clin Orthop Relat Res 2005;432:217-25.

3 Strauss E, Langford JR, Baumgartener MR, et al. Current concepts offered for managing geratric intertrochanteric hip fractures. Orthopedics Today, 2017.

4 Roberts CS, Nawab A, Wang M, et al. Second generation intramedullary nailing of subtrochanteric femur fractures: a biomechanical study of fracture site motion. J Orthop Trauma 2002;16:231-8.

5 Bergmann G, Deuretzbacher G, Heller M, et al. Hip contact forces and gait patterns from routine activities. J Biomech 2001;34:859-71.

6 Crawford CH, Malkani AL, Cordray S, et al. The trochanteric nail versus the sliding hip screw for intertrochanteric hip fractures: a review of 93 cases. J Trauma 2006;60:325-9.

7 Shashikant BG, Wasudeo MG, Pradeep K. Trochanteric buttress plate combined with proximal femoral nail for unstable intertrochanteric fractures. [Innovative technique]. Medicine 2018;8:235-47. https://doi.org/10.4236/ojo.2018.86027 